Canadian University Music Review

Revue de musique des universités canadiennes

\title{
Agathe de Vaux. La petite histoire de l'O.S.M. Montréal : Louise Courteaux éditrice, 1984, 190 pp.
}

\section{Claire Rhéaume}

Numéro 6, 1985

URI : https://id.erudit.org/iderudit/1014074ar

DOI : https://doi.org/10.7202/1014074ar

Aller au sommaire du numéro

Éditeur(s)

Canadian University Music Society / Société de musique des universités

canadiennes

\section{ISSN}

0710-0353 (imprimé)

2291-2436 (numérique)

Découvrir la revue

Citer ce compte rendu

Rhéaume, C. (1985). Compte rendu de [Agathe de Vaux. La petite histoire de l'O.S.M. Montréal : Louise Courteaux éditrice, 1984, 190 pp.] Canadian

University Music Review / Revue de musique des universités canadiennes, (6), 338-339. https://doi.org/10.7202/1014074ar

(c) Canadian University Music Society / Société de musique des universités canadiennes, 1985
Ce document est protégé par la loi sur le droit d'auteur. L'utilisation des services d'Érudit (y compris la reproduction) est assujettie à sa politique d'utilisation que vous pouvez consulter en ligne.

https://apropos.erudit.org/fr/usagers/politique-dutilisation/ 
Agathe De Vaux. La petite histoire de l'O.S.M. Montréal : Louise Courteaux éditrice, 1984, $190 \mathrm{pp}$.

C'est relever un défi imposant que d'écrire l'histoire d'un orchestre symphonique québécois quand tout est à dire. Deux options semblent alors s'offrir à l'auteur d'une telle recherche : l'historiographie sans prétention accessible à tous ou l'ouvrage musicologique détaillé attirant dans son sillage les chercheurs " mordus " de la musique au Québec.

Malencontreusement pour ces fanatiques (je m'expliquerai plus loin), c'est du premier genre que relève La petite histoire de l'orchestre symphonique de Montréal. Mais, pour le grand public mélomane de l'O.S.M., l'auteure, Agathe de Vaux, raconte un bien belle histoire : celle d'un orchestre aux premiers pas trébuchants se dirigeant vers une gloire reconnue, tel que l'on connait l'O.S.M. d'aujourd'hui, cinquante ans après sa fondation.

C'est pourquoi, vu sous cet angle, l'attrait premier de ce petit livre repose dans la simplicité d'expression, l'analyse objective et l'utilisation d'anecdotes (parfois banales mais le plus souvent sympatiques). Ainsi, on apprend qu'au long de son développement cet orchestre a dû faire face à bien des situations cocasses, malicieuses ou désastreuses!

Visiblement, c'est à partir d'une abondante documentation (journaux, interviews, revues musicales, archives) qu'Agathe de Vaux nous entraîne agréablement dans la " petite cuisine » de l'O.S.M. De la salle du Plateau à la Place des Arts, en passant par les Festivals de Montréal, les concerts d'été, et les tournées de l'O.S.M., l'auteur nous parle avec autant de " sérieux " de l'achat des premières cymbales et du premier costume officiel des femmes instrumentistes que de la personnalité des directeurs artistiques et des chefs invités.

À travers les chapitres, on survole toutes les activités musicales et extra-musicales de l'O.S.M. : le comité féminin qi oeuvre bénévolement pour le bien de l'orchestre, les Matinées Symphoniques qui font découvrir la musique aux jeunes, le répertoire musical, le Concours J.C. Lallemand, etc... Tout cela est mené d'une façon " humoristique " par l'intermédiaire d'anecdotes qui allégent la quantité incroyable de noms cités à travers le récit.

Mais pour les chercheurs de la musique au Québec, La petite histoire de l'orchestre symphonique de Montréal aurait pû devenir la grande histoire de l'O.S.M., si l'auteure avait pris soin d'apporter à son ouvrage des éléments inhérents à toute étude musicologique : références précises, bibliographie adéquate, index détaillé, précision chronologique, etc. Ces informations incomplètes ou manquantes constituent la grande lacune de ce livre du point de vue de la recherche musicologique. Cependant, il faut préciser que La petite histoire de l'orchestre symphonique de Montréal n'offre pas la prétention de couvrir le sujet de A à $\mathrm{Z}$...

En somme, ce livre demeure très plaisant à lire et donne quand même une excellente idée d'ensemble de ce que furent les cinquante premières 
années de l'Orchestre Symphonique de Montréal et ce, dans la mesure où l'on veut bien se laisser raconter une belle histoire de coeur!

Claire Rhéaume

DÉRIVES, No 44-45, 1984, " Musique contemporaine au Québec », sous la direction de Marcelle Guertin, 156 pages ill., et un disque $33 \mathrm{t}$., $17 \mathrm{~cm}$.

À l'occasion des Journées mondiales de la musique organisées par la S.I.M.C. en octobre 1984 à Montréal, la revue Dérives publie un numéro spécial consacré à l'étude des divers aspects de la musique contemporaine au Québec ; un disque reproduisant des extraits de "Lignes et points " (1964) de Pierre Mercure et de "Lonely Child " (1980) de Claude Vivier accompagne ce numéro. Cet ensemble d'articles ne prétend pas apporter des faits nouveaux à caractère historique sur ce sujet, mais se présente sous forme de bilan et offre une vue d'ensemble de la multiplicité des tendances actuelles. Compte tenu que nos derniers " bilans " historiques datent de 1964 (Lásalle-Leduc, A., La vie musicale au Canada français) et de 1971 (Duguay, R., Musiques du Kébek), ce numéro de Dérives comble donc une lacune importante au niveau de l'information. La présentation de points de vue différents exprimés par une variété d'intervenants du monde musical sur notre musique " telle que rêvée, composée, interprétée, diffusée et reçue " permet au lecteur de saisir cette réalité à la fois complexe et méconnue.

Parmi les onze articles proposés, huit présentent un caractère inédit ; la présentation de Marcelle Guertin confronte le lecteur aux multiples résonnances du terme " contemporain ", alors que les commentaires des compositeurs Garant et Tremblay démontrent la perpétuelle remise en question des créateurs ; il est d'ailleurs intéressant, à ce propos, de lire immédiatement après, les réflexions du jeune compositeur Michel Gonneville, pour observer les points de convergence et la "différence pacifique " entre ces deux générations.

Les interrogations sur le théâtre musical présentées par Gisèle Ricard, sous forme d'aventure biographique dans un style piquant et humoristique, trouvent une certaine complémentarité dans les commentaires de Micheline Coulombe-Saint-Marcoux sur son oeuvre Transit (dernier écrit de cette compositrice, décédée en février 1985), rapportés par Jean Jonassaint.

À cause de la rareté des écrits des interprètes sur les problèmes d'interprétation de la musique contemporaine, l'article de Marcelle Guertin et de Javier Garcia Mendez réalisé à partir d'échanges informels avec Lorraine Vaillancourt, elle-même interprète très appréciée du public des Événements du Neuf et de l'Atelier de musique contemporaine de la Faculté de musique de l'Université de Montréal, est peut-être celui qui éclaire le plus le lecteur sur le renouveau musical qu'ont proposé les 